\title{
Model for Monitoring Sustainable Green SLA Parameters in Modern Computing Industries
}

\author{
lqbal Ahmed \\ Dept. of Computer Science and Engineering \\ University of Chittagong \\ Chittagong, Bangladesh
}

\begin{abstract}
Green SLA (GSLA) is a formal agreement between service providers/vendors and users/customers incorporating all the traditional/basic commitments (Basic SLA) as well as respecting the Ecology, Economy and Ethics (3Es) for sustainable development. Nowadays, modern computing industries such as IT (Information Technology) and ICT (Information and Communication Technology) are trying to incorporate sustainability under green computing lens. At the same time, users/customers are also moving forwards to a new sustainable society. Therefore, while getting or providing various services from many computing industry, GSLA becomes significant for both the service providers and users/customers to achieve sustainability in their field. Moreover, most of the basic SLA parameters are quantitative and they are simple, easy to evaluate, control and monitor whereas GSLA parameters are difficult to monitor, and there are very few research have done in this area. This research proposes an idea to evaluate and monitor some important newly identified green parameters through interacting basic SLA parameters in the networking domain of modern computing industries. The proposed idea will be guideline for the green expert/CEO of ICT/IT industries to incorporate green parameters in their GSLA to achieve sustainability.
\end{abstract}

\section{General Terms}

Green Computing, Sustainable Computing, Basic SLA, Green SLA, Computing Industries, Network monitoring.

\section{Keywords}

Basic SLA; GSLA; Monitoring Parameters; Networking; Sustainability.

\section{INTRODUCTION}

Recently, many computing industries including cloud, grid computing and data centers maintain SLAs or GSLAs at various level to inform their customers/users the inherent executional functions and even some non-functional quality of service[1]. The basic SLAs only cover traditional commitments, which are very easy to evaluate for both sides, whereas GSLA is getting importance for sustainability achievement in their scope, and still far to go in case of real implementation. Currently, the continuous increase in global carbon footprint is due to the revolution of IT/ICTs and its usages in our daily life. The ICT sector produced as much GHG as the aero industry in 2007 and is projected to growing sharply [2, 3]. Additionally, the reduction of energy consumption, the rise of environmental awareness, the effective communication for environmental issues, - were the main three dimensions of green informatics contribution to the modern society [4]. Therefore, many modern computing industries need to think their business scope under the dimensions of green computing. Therefore, with the increase attention of green informatics and sustainability, it is timely to not only conduct SLAs for traditional/basic computing parameters but also to relate the effort of conducting green computing with respect of Ecology, Economy and Ethics (3Es) of sustainability. In addition, the expedition of GSLA is already started in the computing industries in many developed country [5]. However, the designing and monitoring sustainable GSLA parameters are giving hard time for the ICT engineer/ green expert CEO in the industry. The already identified new parameters for sustainable GSLA and global informational model definitely assists the industry to deploy a sustainable GSLA [6]. Very few work have been found regarding the monitoring aspects of GSLA parameters [7]. This research proposes the idea of monitoring green parameters through interacting some already identified basic SLA parameters under networking domain in the computing industry. The idea illustrated through an UML model, which would be a guideline in this field. The proposed GSLA monitoring model would be helpful for the ICT engineer to evaluate and monitor green parameters under $3 \mathrm{Es}$ of sustainability.

\section{BACKGROUND CHECKS}

Many works and research have been carried out on basic SLAs and few GSLA. The details literature review done by setting some identical keywords and analytical criterion metric/parameters identifying, service identifying, green computing practice, SLA development methodology, implementation, monitoring aspects of various SLAs from many researchers.

\subsection{Basic SLAs}

The existing research on basic SLA implementation, management, automation, template design and monitoring in the context of business requirement [7]. Most of the basic SLAs works are divided into four main domains of computing industries - Network, Compute, Storage and Multimedia [8]. Mostly all the basic SLA parameters are quantitative and they are simple, easy to evaluate, control and monitor. Therefore, it is easy to consider most of the basic performance based parameters from both customer and providers side. Due to simplicity, this work considering only the few parameters of network domain for modeling the monitoring aspects of future sustainable GSLA. The basic SLAs for Compute, Storage and Multimedia domain are already discussed briefly in [7]. However, it is worth to mention that, the basic SLAs from various domain did not cover any eco-efficient green parameters.

\subsubsection{Basic SLAs for Networking Domain}

Generally, from different network service providers, the following performance based parameters found in their SLAs, Network Availability, Delay, Latency, Packet Delivery Ratio, 
Jitter, Congestion, Flow Completion time, Response time, Bandwidth, Utilization, MTBF (Mean Time Between Failure), MTRS (Mean Time to Restore Services), Solution time, Resolution time, LAN/WAN period of operation, LAN/WAN Service Time, Internet access across Firewall, RAS (Remote access Services) [6,7]. few parameters like Bandwidth, Utilization, and Congestion are related to link capacity whereas Availability, Delay, Jitter, Response Time etc. associated with time related information for various network service providers. All these parameters are easy and simple to monitor and evaluate by using existing $\mathrm{s} / \mathrm{w}$ and $\mathrm{h} / \mathrm{w}$ tools in real time network architecture.

\subsection{Green SLAs}

The Table 1 represents the analysis of exiting GSLAs works under few criteria, such as green services and operations, practicing green aspects, green metrics information, framework development and evaluation/monitoring. Very few research discussed IT ethical issues. The cell indicated with "YES" means that, the researchers either mentioned and worked on that criteria of existing green SLAs research. It is evident from the Table 1 that, very few works have been done in the monitoring aspects of GSLAs (only two).

Table 1. Analysis of Existing GSLA works

\begin{tabular}{|c|c|c|c|c|c|c|}
\hline \multirow{2}{*}{$\begin{array}{c}\text { Author Lists, } \\
\text { adopted from [6] }\end{array}$} & \multicolumn{6}{|c|}{ Analysis Criteria } \\
\hline & $\begin{array}{c}\text { Green } \\
\text { Services \& } \\
\text { Operations }\end{array}$ & $\begin{array}{c}\text { Practice of } \\
\text { Greening } \\
\text { Computing }\end{array}$ & $\begin{array}{c}\text { Green } \\
\text { Metrics } \\
\text { Information }\end{array}$ & $\begin{array}{c}\text { Framework/ } \\
\text { Implementation } \\
\text { Methodology/ }\end{array}$ & $\begin{array}{c}\text { Assessment/ } \\
\text { Monitoring/ } \\
\text { Evaluation }\end{array}$ & $\begin{array}{c}\text { IT } \\
\text { Ethical } \\
\text { Aspects }\end{array}$ \\
\hline L Wu 2011 et al. & & YES & & & & YES \\
\hline Z. S. Andreopoulou 2012 & & YES & & & & YES \\
\hline Klingert 2011 et al. & YES & YES & & & & \\
\hline Li 2011 et al. & & YES & & YES & & \\
\hline G. V Laszewski 2010 et al. & YES & YES & YES & YES & & \\
\hline Md. E. Haque 2013 et al. & & & & YES & YES & \\
\hline Kien Le 2010 et al. & & & & YES & & \\
\hline M. Nichollas 2010 & & & & & & YES \\
\hline R R. Harmon 2009 et al. & YES & YES & YES & & & \\
\hline Ahmed 2015 et al. & YES & YES & & & YES & \\
\hline N Agarwal 2012 et al. & YES & YES & & & & \\
\hline A. P Bianzino 2010 et al. & YES & YES & & YES & & \\
\hline A. Atrey 2013 et al. & & YES & YES & YES & & \\
\hline A. Orgerie 2014 & YES & YES & & & & \\
\hline Fritz H. Grupe 2002 et al. & & & & YES & & YES \\
\hline R. Herold 2015 & & & & & & YES \\
\hline
\end{tabular}

\subsection{Existing Green SLA Parameters}

Nowadays, many modern computing (IT and or ICT) industries, cloud providers and data centers provide their GSLAs under green computing practice. These GSLAs are mainly focused only on, - energy/ power, carbon footprint, recycling issues. Several existing green SLA also represents their productivity issues with necessary monitoring unit. Moreover, many research mainly draws attention only on minimizing energy consumption while improving networking performance on wireless connection in the lens of green computing $[9,10]$. All these green parameters (Table 2) help many ICT/IT service providers and customers either to design or to choose services mainly with respect to energy/power consumption, different renewable energy usages, carbon emission/GHG emission and productivity issues. However, the ICT industry needs to find out new parameters for achieving sustainability as current trends of the society shows that people are much more concerned about sustainability in this scope while many research are just going on practicing green computing $[3,4,11,12,13,14]$. Table 2 depicts the parameters and their unit for different services considering green computing practices. The table with headings, Green Computing Domain mentions the category of green computing practices in computing industry; Performance Indicator Name means the parameters which used for evaluating, monitoring metric for defining performance in GSLAs, and then their measurable unit as Unit column.

\section{DEFINING OF GSLA UNDER 3Es OF SUSTAINABILITY}

Next, Figure 1 depicts the idea to define new GSLA under sustainability lens (3Es). Current focus represents the basic SLA parameters and very few green parameters in the ICT/IT industry. In existing green SLAs, many of the parameters 
mainly focus on energy/power consumption and productivity issues in cloud and grid computing industry (Table 1). However, the existing GSLA stills missed out most of the significant parameters for sustainable development. In addition, people's interaction and ethical issues are also missing in existing GSLA [8]. Thus, the newly focused part identify the concepts of 3Es (Ecology, Economy and Ethics) relationship with current GSLA, which will be the guideline for ICT engineer to design and respect all the parameters of sustainable GSLAs under 3Es perspectives. Therefore, according to Figure 1, "sustainable GSLA need to aggregate and satisfy all three main pillar of sustainability - Ecology, Economy, and Ethics". There must be trade-offs between 3Es to achieve sustainability in the scopes.

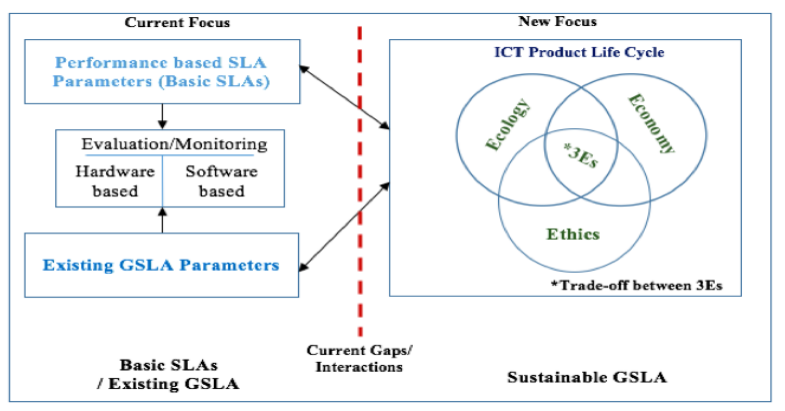

Fig 1: Sustainable GSLA from 3Es Perspectives

Under Ecology the following new parameters are considering while developing new services or application in the ICT field, - Recycling, ICT Toxic Material Information, Radio Wave Information, Obsolescence Indication, Noise Visual Light Pollution [6]. In addition, Economic Pillar added also new parametrs in future GSLA, - Carbon Taxation, ICT Product Life Cycle Cost, Civil Engineering Cost, Cooling cost [6]. Moreover, in most ICT/IT modern industries, the green computing practices focuses few of the ecological, economical parameters but usually neglect/avoid human's interaction and ethics issues [15]. The use of ethics in IT and ICT field cover many parameters, for example Satisfaction level, Intellectual Property Right, Reliability, Confidentiality, Security and Privacy, Gender/Salary/Productivity Information [6]. The modern ICT/IT industries need to analyze their social responsibilities towards their customer, employee and community through IT Ethics program and guideline $[15,16]$. Most of these ethical parameters are usually very much subjective and informative, therefore making GSLA evalution and monitoring very difficult. It is clear from the figure. 1 that, still there is no proper monitoring aspects of all newly identified new focus of sustainable GSLA.

Due to simplicity, this work mainly focus on monitoring three green parameters: (1) Power Consumption (2) Carbon Emission and (3) Product Life Cycle time. It is clear from the Table 1 that, Power/energy and GHG emission and/or Carbon emission is the main concern in green computing industries. The product life cycle plays important role as this parameter interacts with all ICT/IT related devices. Therefore, the monitoring aspects of these three green parameters is significant for deploying GSLA. Next section represents the way of monitoring these parameters under 3Es of sustainability. The model of monitoring these parameters would be used as a future guideline for the ICT engineer.
Table 2. Parameters of different services considering existing GSLA, adopted from [6]

\begin{tabular}{|c|c|c|}
\hline $\begin{array}{c}\text { Green } \\
\text { Computing } \\
\text { Domain }\end{array}$ & $\begin{array}{l}\text { Performance Indicator } \\
\text { Name/Parameters }\end{array}$ & Unit \\
\hline \multirow{15}{*}{$\begin{array}{l}\text { Related to } \\
\text { Energy/ } \\
\text { Power } \\
\text { Consumption } \\
\text { and Usages }\end{array}$} & Total Power Consumption & $\begin{array}{c}\text { kW-h } \\
\text { (Kilowatt- } \\
\text { hour) }\end{array}$ \\
\hline & $\begin{array}{l}\text { PUE (Power Usages } \\
\text { Effectiveness ) }\end{array}$ & $\begin{array}{c}\text { Number }(1.0 \\
\text { to } \infty) \text { Or } \\
\text { Dimensionless }\end{array}$ \\
\hline & $\begin{array}{c}\text { DCiE ( Data Center } \\
\text { Infrastructure Efficience) }\end{array}$ & $\%$ (Percentage) \\
\hline & $\begin{array}{l}\text { CPE (Compute Power } \\
\text { Efficiency) }\end{array}$ & Watts \\
\hline & SPECPower & Watt \\
\hline & JouleSort & $\mathrm{kW} / \mathrm{J}$ \\
\hline & $\begin{array}{l}\text { WUE (Water Usages } \\
\text { Effectiveness) }\end{array}$ & Liter/kW-h \\
\hline & $\begin{array}{l}\text { TDP (Thermal Design } \\
\text { Power) }\end{array}$ & Watts \\
\hline & ERF (Energy Reuse Factor) & $\begin{array}{l}\text { Number } \\
{[0 \text { to } 1.0]}\end{array}$ \\
\hline & $\begin{array}{l}\text { ERE (Energy Reuse } \\
\text { Effectiveness) }\end{array}$ & $\begin{array}{l}\text { Number } \\
{[0 \text { to } \infty]}\end{array}$ \\
\hline & $\begin{array}{l}\text { GEC (Green Energy Co- } \\
\text { efficient) }\end{array}$ & $\begin{array}{l}\text { Number } \\
{[0 \text { to } 1.0]}\end{array}$ \\
\hline & $\begin{array}{l}\text { ITEE (IT Equipment Energy } \\
\text { Efficiency) }\end{array}$ & $\%$ (Percentage) \\
\hline & $\begin{array}{c}\text { ITEU (IT Equipment } \\
\text { Utilization) }\end{array}$ & Number \\
\hline & $\begin{array}{c}\text { HVAC (Heating, } \\
\text { Ventilation, Air- } \\
\text { conditioning) Effectiveness }\end{array}$ & Dimensionless \\
\hline & Cooling System Efficiency & $\mathrm{kW} / \mathrm{ton}$ \\
\hline \multirow[t]{2}{*}{$\begin{array}{l}\text { Carbon } \\
\text { footprint }\end{array}$} & $\begin{array}{l}\text { CUE(Carbon Usages } \\
\text { Effectiveness) }\end{array}$ & $\begin{array}{l}\mathrm{KgCO} 2 \text { per } \\
\text { kW-h }\end{array}$ \\
\hline & $\begin{array}{c}\text { DPPE (Data Center } \\
\text { Performance Per Energy) }\end{array}$ & $\begin{array}{l}\text { Number } \\
{[0 \text { to } 1]}\end{array}$ \\
\hline \multirow[t]{3}{*}{ Recycling } & e-Wastage Or IT Wastage & Gm (Gram) \\
\hline & Recycling & $\%$ (Percentage) \\
\hline & $\begin{array}{l}\text { DCP (Data Center } \\
\text { Productivity) }\end{array}$ & Not Available \\
\hline Related to & $\begin{array}{l}\text { DCeP (Data Center Energy } \\
\text { Productivity) }\end{array}$ & Not Available \\
\hline
\end{tabular}




\begin{tabular}{|c|c|c|}
\hline \multirow{4}{*}{$\begin{array}{c}\text { Productivity } \\
\text { issues }\end{array}$} & Analysis Tool & Not Known \\
\cline { 2 - 3 } & EnergyBench & $\begin{array}{c}\text { Numeral } \\
\text { Rating }\end{array}$ \\
\cline { 2 - 3 } & $\begin{array}{c}\text { ScE (Server Compute } \\
\text { Efficiency) }\end{array}$ & \%(Percentage) \\
\hline $\begin{array}{c}\text { Costing } \\
\text { Information }\end{array}$ & Energy/Power Cost & Currency \\
\hline \multirow{4}{*}{ Others } & $\begin{array}{c}\text { SWaP (Space, Wattage and } \\
\text { Performance) }\end{array}$ & Not Available \\
& & \\
& Air Management Metric & F (Fahrenheit) \\
\cline { 2 - 3 } & UPS System Efficiency & $\%$ (Percentage) \\
\cline { 2 - 3 } & & \\
\hline
\end{tabular}

\section{MONITORING GREEN PARAMETERS FOR SUSTAINABLE GSLA}

Sustainability can be achieved through proper definition of GSLA under 3Es, which largely depends on monitoring the indicators [16]. Therefore, this research draws attention on the monitoring the parameters for better performance and validation. Another significant dimension about monitoring sustainable GSLA is that - the ICT engineers able to monitor and analyze about both basic SLA (e.g., delay, jitter, uptime etc.) and ecological parameters (e.g., energy consumption, GHG emission, recycling etc.) simultaneously. Additionally, most of the network service provider provides following performance based parameters in Basic SLAs Network Availability, Delay, Latency, Packet Delivery Ratio, Jitter, Congestion, Flow Completion time, Response time, Bandwidth, Utilization, MTBF (Mean Time Between Failure), MTRS (Mean Time to Restore Services), Solution time, Resolution time, LAN/WAN period of operation, LAN/WAN Service Time, Internet access across Firewall, RAS (Remote access Services)[6, 7]. Some parameters like Bandwidth, Utilization, and Congestion are directly related to the link capacity whereas Availability, Delay, Jitter, Response Time etc. associated with time related information. All these parameters are easy, simple to monitor and evaluate by using few $\mathrm{h} / \mathrm{w}$ and/or $\mathrm{s} / \mathrm{w}$ tool. This particular idea leads this research to establish a relationship between basic SLA and green parameters. Indeed, basic SLA is currently monitored and if the relationships between basic SLA and green parameters are discovered, then the monitoring of GSLA will be simplified and easy. In order to show the relationships between the basic SLA parameters and green parameters, this work review on the following three important parameters: energy/power consumption of a switch, carbon emission and ICT lifetime costs.

\subsection{Power/Energy Consumption of a CISCO Switch (Usage Phase)}

The power/energy consumption measurement of a complete network is very hard because of the diverse and dynamic nature of the whole system. There are several research works on modeling network power/energy consumption and their management $[17,18]$. The power consumption measurement of a switch is calculated from the 03 basic SLA parameters bandwidth, number of PC connected and link load [17]. Here, the works consider the switch architecture (CISCO 2960 EnergyWise) at the usage level to represent the relationships between basic network SLA parameters and power usage [17]. The next (1) is proposed by the authors and this equation can be scaled for a network to calculate the power/energy consumption of the whole network [17].

Power $=33.2708-0.000318$ Bandwidth +0.05156 PC Connected -0.001329 Link Load +0.000253 Bandwidth* PC Connected + 0.000006 Bandwidth * Link Load + 0.000477 PC Connected * Link Load (1)

Presently, these 03 basic network SLA parameters are monitored in any network monitoring system. Thus, the above equation is used to model the monitoring of power consumption of a switch during the usage level. The power measurement model [18] needs to be included to get more precise power consumption measurement in future. The energy/power consumption of the network architecture can be easily obtained both directly by EnergyWise and indirectly by using the equation [17]. The interest of this approach is to compare real measurement (using EnergyWise) with indirect measurement (1). If there is a deviation between these two measures, it can be assumed that there are anomalies (e.g., disconnection of PCs, links) in the network system. From this approach, such relationship defined by the equation not only develops a system for monitoring energy consumption, but also enables smart monitoring system using basic network SLA indicators. In addition, in many cases, anomalies cannot be detected correctly by the monitoring tool of basic SLA. In those cases, a system of cross validation derived from basic SLA monitoring can be very effective and opens scopes for further analysis. All these three basic network SLA parameters can be used for deriving power/energy consumption parameters for future GSLA.

\subsection{Carbon Emission (Usage Phase)}

The next most important and burning issue is the carbon emission regarding green IT and sustainable development. Carbon emission is calculated from the measurement of energy consumed by IT/ICT architecture and from the $\mathrm{CO}_{2}$ factor (per $\mathrm{kWh}$ ) provided in real time by RTE, France (Réseau de Transport d'Électricité) [8]. The carbon emission need to be calculated from the energy consumption during the whole life cycle of an ICT product using Carbon Factor, which are the matching rate between energy consumption and carbon emission in electricity production in their respective countries [17]. Figure 2 shows a real time scenario of carbon emission and energy consumption relationships [8]. The carbon emission and energy consumption can also be derived using previous work [18]. Thus, carbon emission can be evaluated and monitored from the basic SLA parameters.

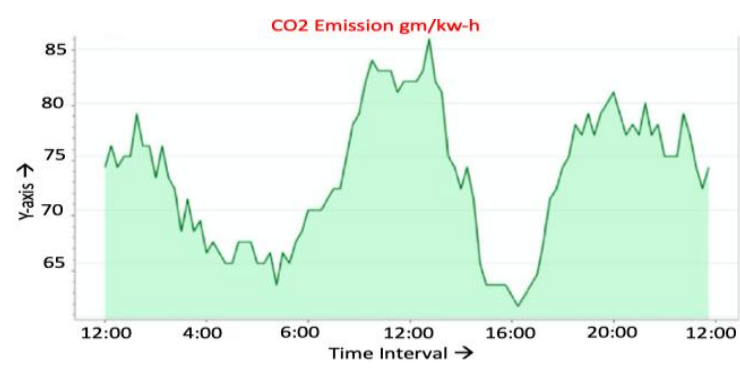

Fig 2: Real time Energy Consumption and Carbon Emission relationship using $\mathrm{CO} 2$ factor from RTE, France. 


\subsection{ICT Product Life Cycle (LCA) Time}

Another significant parameters of future GSLA is to evaluate the product life cycle time and their cost. The maximum allowable life time can be decreased in accordingly with the interactions of basic SLA parameter, - MTTR (Mean Time To Reparation) costs and power saving parameter of the ICT devices. The next equation in the Figure 3 is derived to depicts the relationship $[19,20]$. In addition, this parameter is also important to respect user satisfaction under ethics pillar of sustainability.

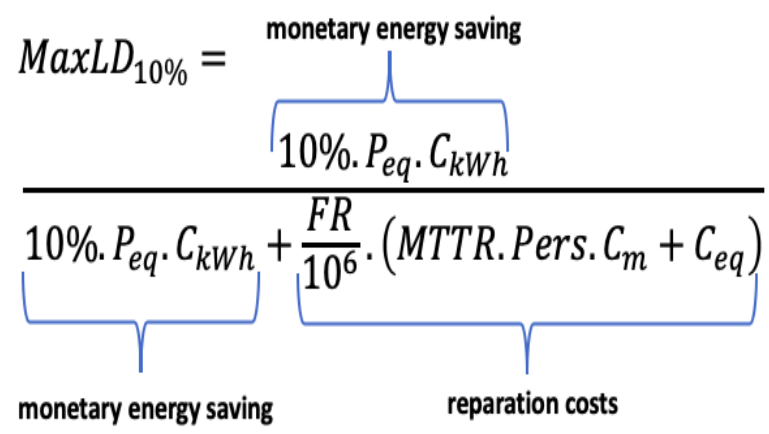

Fig 3: ICT Product Life Time with MTTR and power savings, adopted from [20]

Moreover, the complete life cycle of ICT product need to consider here to get more precise results [6,7]. Therefore, the monitoring of this parameters might be more difficult in future GSLA.
The following UML (Unified Modeling Language) Model (Figure 4) illustrates the interrelations of basic SLA parameters with three main green parameters of GSLA (energy consumption, carbon emission and ICT product life costing) to respect the mentioned three examples in previous sections in any networking architecture. The UML represents high level abstraction of the basic SLA parameters, defined by four general network related indicators. It is definite and clear from the model that monitoring future sustainable GSLA parameters is possible using the basic network SLA parameters.

This section discovers the scope of monitoring and evaluating the three important GSLA parameters (Power Consumption, Carbon Emission and ICT product Life Time) by showing their relationships with traditional basic SLA parameters (Capacity, Congestion, Component and Connectivity Indicators). However, most of the green parameters are still difficult to measure directly. They are non-technical and depend on human interaction in some case. On the other hand, basic SLA parameters are easily measurable and already monitored by many s/w and/or $\mathrm{h} / \mathrm{w}$ tools. Therefore, for most of the proposed GSLA parameters [5,6], it is not easy to establish such relationships. Hence, monitoring of all of the green parameters proposed in [5] is still a challenging task for sustainability achievement and leave an open space for future research.

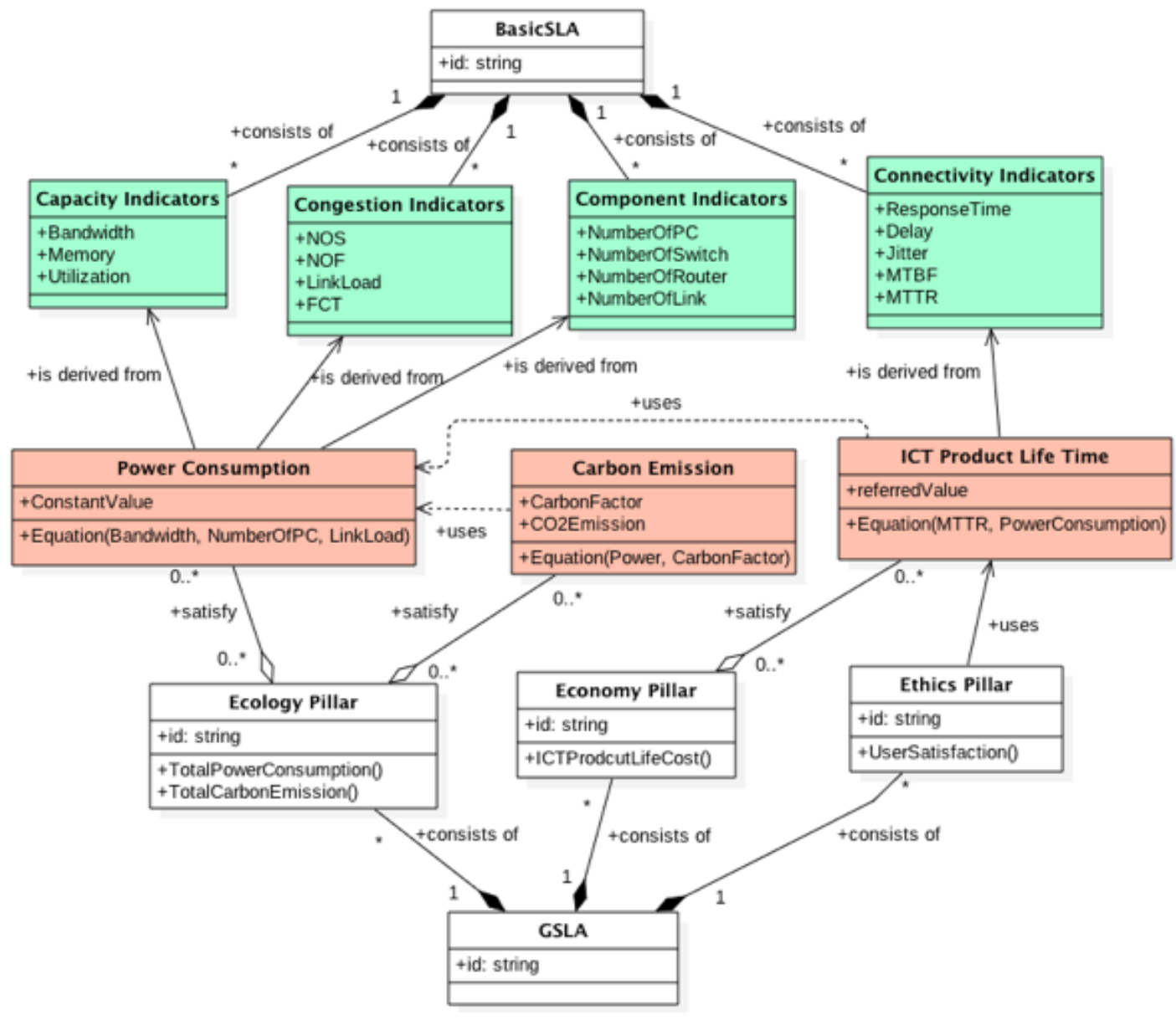

Fig 4: The interaction model of Basic SLA parameters and GSLA parameters (Power Consumption, Carbon Emission and ICT Product Life Cycle Time) 


\section{CONCLUSION}

The main achievement of this research is finding the direction of monitoring and evaluating green parameters under sustainability lens. The interaction of easily identified basic SLA parameters and green parameters would definitely lead a new idea in the field of sustainable GSLA development in ICT industries. The authors believe, the UML notation in Figure 4 and their corresponding examples could be used while designing third-party monitoring tool future sustainable GSLA. The future of this research can be identifying more new green parameters for monitoring and simulate the idea proposed here. However, major challenges for designing sustainable future GSLA are, - new parameters need to be defined correctly which has association with other parameter; also most of the subjective, qualitative parameters related with ethics and human behavior need standardization or governed and authorized by new laws and directives.

\section{REFERENCES}

[1] Wu, L. and Buyya, R. 2011. Service Level Agreement (SLA) in Utility Computing Systems. Performance and Dependability in Service Computing: Concepts, Techniques and Research Directions, V. Cardellini et. al. (eds), ISBN: 978-1-60-960794-4, IGI Global, Hershey, PA, USA, pp.1-25.

[2] Mankoff, J., Kravets, R. and Blevis, E. 2008. Some Computer Science Issues in Creating a Sustainable World. Computer, Vol. 41, No. 8.

[3] SMART 2020 Report. 2008. Enabling the low carbon economy in the information age. The Climate Group, GeSI.

[4] Andreopoulou, Z. S. 2012. Green Informatics: ICT for Green and Sustainability. Journal of Agriculture Informatics (EIFTA), Vol. 3, No. 2.

[5] Ahmed, I., Okumura, H. and Arai, K. 2016. An Informational Model as a Guideline to Design Sustainable Green SLA (GSLA). International Journal of Advanced Computer Science and Applications, Vol.7, No.4, pp. 302-310.

[6] Ahmed, I., Okumura, H. and Arai, K. 2015. Analysis on Existing Basic Slas and Green Slas to Define New Sustainable Green SLA. International Journal of Advanced Computer Science and Applications, Vol.6, No.12, pp. 100-108.

[7] Jiang, D., Zhengzheng, X. and Zhihan L.V. 2015. A multicast delivery approach with minimum energy consumption for wireless multihop networks. Journal of telecommunication Systems, pp. 1-12.

[8] Jiang, D., Ying, Y., Han Y. and Zhihan L.V. 2015. Collaborative multi-hop routing in cognitive wireless networks. Journal of Wireless Personal Communications, pp. 1-23.
[9] Duncombe, J.U. 1959. Infrared navigation-Part I: An assessment of feasibility (Periodical style). WASET Trans. Electron Devices, vol. ED-11, pp. 34-39.

[10] Amokrane, A., Zhani, M.F. Qi Zhang, R., Langar, R., Boutaba, R. and Pujolle, G. 2014. On Satisfying Green SLAs in Distributed Clouds. $10^{\text {th }}$ International Conference on Network and Service Management (CNSM), pp. 64-72.

[11] Bianzino, A. P., Chaudet, C., Rossi, D. and Rougier, J. 2010. A Survey of Green Networking Research. IEEE Communication Surveys and Tutorials, Vol. 14, Issue. 1, pp. 3-20.

[12] Atrey, A., Jian, N. and Iyengar, N.Ch.S.N. 2013. A Study on Green Cloud Computing. International Journal of Grid and Distributed Computing, Vol. 6, No. 6, pp. 93102.

[13] Orgerie, A. C. 2014. A Survey on Techniques for Improving the Energy Efficiency of Large Scale Distributed Systems. ACM Computing Surveys (CSUR), Vol. 46, Issue 4.

[14] Rondeau, E., Lepage, F., Georges, J.P. and Morel, G. 2015. Measurements and Sustainability. Chapter 3, Green Information Technology, 1st Edition, A Sustainable Approach, Dastbaz \& Pattinson \& Akhgar, ISBN: 9780128013793, Elsevier Book, 304 pages.

[15] Shirazi, N., Schaeffer, A. and Hutchison, D. 2012. Service Level Agreement Monitoring for Resilience in Computer Networks. 13th Annual Post Graduate Symposium on The Convergence of Telecommunications, ISBN: 9781902560267, Liverpool, United Kingdom.

[16] Hossain, Md., Rondeau, E., Georges, J.P., and Bastogne, T. 2015. Modelling the Power Consumption of Ethernet Switch. 2015 International SEEDS Conference, Leeds Beckett University, United Kingdom.

[17] Moro, A. and Lonza, L. 2018. Electricity Carbon Intensity in European Member States: Impacts on GHG Emissions of Electrical Vehicles. Transportation Research Part D 64, pp. 5-14.

[18] Beister, F., Draxler, M., Aleken, J. and Karl, H. 2014. Power model design for ICT systems - A generic approach. Computer Communication Journal, Vol. 50 (Special Issue), pp. 77-85.

[19] Bruschi, R., Lago, P., Lombardo, A. and Schembra, G. 2014. Modeling power management in networked devices. Computer Communication Journal, Vol. 50 (Special Issue), pp. 95-109.

[20] Chiaraviglio, L., Wiatr, P., Monti, P., Chen, J., Lorincz, J., Idzikowski, F., Listanti, M. and Wosinska, L. 2015. Is Green Networking Beneficial in Terms of Device Lifetime? IEEE Communications Magazine. 